\title{
Are Polar Continental Shelves Economic to 'Farm' for Increased Carbon Capture and Storage?
}

\author{
Barnes DKA* and Sands CJ \\ BAS Marine Ecologist, University College Cork, Europe \\ *Corresponding author: BAS Marine Ecologist, University College Cork, Europe, Cambridge, CB24 9PE, UK \\ Submission: 进 February 3, 2018; Published: 侮 March 15, 2018
}

\begin{abstract}
Carbon-capture and storage (CCS) is expensive but as commercialization is proving problematic and economic estimates of climate change costs escalate, non-mainstream alternatives should be discussed. We present a thought experiment based on potential for increased carbon capture on polar continental shelves. West Antarctic, and probably Arctic, continental shelves are sites of significant negative feedbacks on climate change through benthos carbon accumulation. At South Georgia, moraines on the margins of the continental shelf (bulldozed there by past glaciations) show much more biological richness and activity than the typical mud covering $\sim 88 \%$ of the shelf. We estimate that most carbon accumulation, and ultimately sequestration, occurs at these moraines ( $12 \%$ of shelf). Seabed CCS by benthos could increase $400 \%$ if it was all rubble. We think this could be achieved with minimal environmental impacts but at current CCS values it would take 10,000 years (Antarctic) and 1000 years (Arctic) to recoup transport costs. Keywords: Carbon immobilization; benthos; South georgia; $\mathrm{CO}_{2}$; Antarctica
\end{abstract}

\section{Introduction}

Managing and reducing atmospheric carbon $\left(\mathrm{CO}_{2}\right)$ is one of the greatest societal challenges. Drax, a key player in UK commercial carbon-capture and storage (CCS), have tried and failed to make carbon capture pay. Initiating low carbon energy generation, such as through nuclear, wind and solar, requires very considerable capital and thus repayment of interest costs. With escalating estimates of the cost of climate change to economies [1], failure to make carboncapture commercially viable and long build time of nuclear plants, now is the time to consider additional alternatives. Here we present a thought experiment based on potential for increased carbon capture on an example polar continental shelf-that of South Georgia in the Atlantic sector of the Southern Ocean.

Sea-ice losses over West Antarctica's and Arctic continental shelves are making them sites of global significant carbon accumulation and negative feedbacks on climate change [1]. This seems mainly due to higher annual growth of benthos driven by longer duration phytoplankton blooms [3]. Such sinks, even if combined with other negative feedbacks such as ice shelf loss $[4,5]$ and hypoboreal forest growth[6] remain small in comparison with anthropogenic carbon emissions. Furthermore carbon accumulation on some continental shelves, such as at South Georgia, is considerably lower than expected given the lack of seaice and long phytoplankton blooms [3]. Recent advances in multi beam swath seabed mapping, the development of high resolution imagery and underwater camera lander systems and research facilities on board oceanographic vessels are giving powerful new insights into seabed organismal carbon capture and storage. High resolution mapping of seabed surface characteristics and habitat distributions on South Georgia's continental shelf have enabled investigation of how carbon accumulation varies in space and time in such environments. We investigated benthos carbon accumulation performance on moraines (bulldozed there by past glaciations [7]) with more typical mud covered areas around South Georgia. Anecdotal information from fishing boats and biodiversity records suggests that South Georgia's continental shelf moraines may be anomalous and important areas of benthic growth see Hogg et al. [8]. We compared biological characteristics at moraines there with those on other typical soft sediment habitats and discuss whether increasing such rubble areas would
a) significantly increase carbon drawdown,
b) be financially and carbon economical, and
c) have positive ecological impacts?

\section{South Georgia's shelf moraines}

Nearly 50mya the "Azolla event", fern growth in a large arctic lake, drew down and sequestered so much carbon $\left(1.5 \mathrm{~kg} / \mathrm{m}^{2} / \mathrm{yr}\right)$ that it significantly contributed to a five-fold reduction in aerial $\mathrm{CO}_{2}$, and a major drop in global temperatures [9]. Polar shelves are now important carbon sinks and have probably been so during each interglacial period and, as during the Azolla event, rare negative feedbacks on climate change [2]. The magnitude of these is modest, and multiple deployments of a bespoke camera lander (SUCS) 
and trawls around the Marine protected areas of South Georgia and the South Orkney Islands reveal why. Multi beam and TOPAZ seabed mapping, coring and camera lander photographs shows that $\sim 88 \%$ of the continental shelves of these regions are sediment [7]; 'deserts' of epifauna. The $12 \%$ remainder is mainly rubble of glacial moraines (Figure 1). Multiple replicate camera lander deployments at each of 34 locations across two scientific cruises of the RRS James Clark Ross showed that richness (across taxonomic levels) and density of mega and macro-epifauna was $\sim 3$ and $\sim 6$ times higher respectively Table 1 . Estimates of carbon standing stock, drawdown and sequestration were even higher (Table 1). The majority of carbon drawdown, and ultimately sequestration, on South Georgia's and South Orkney Islands continental shelves may be occurring at these moraines, which occupy just $12 \%$ of their extent.
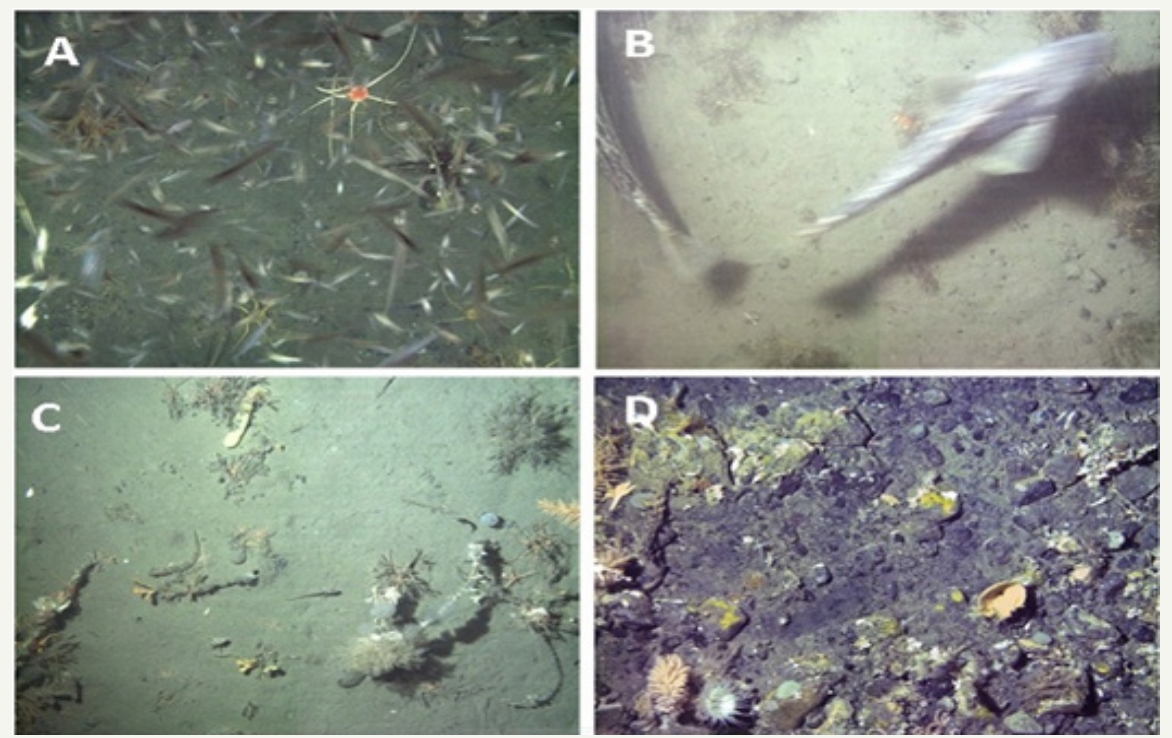

Figure 1: Life on continental shelf morraines at South Georgia (A-C) and the South Orkney Islands (D). Morraines hundreds of meters deep seem to be important as feeding grounds for pelagic krill A), no to the nioid fish (B) and as rich as coral reefs at higher taxonomic levels $(\mathrm{C})$.

Table 1: Biological characteristics of rubble (moraines) and sediment habitats on the South Georgia continental shelf, Southern Ocean. Data given are mean (and standard error) values for epifaunal and 'Vulnerable Marine Ecosystem' density, taxa only seen in one of the habitat types and estimates of carbon drawdown and sequestration. Unique taxa are the number of morpho types only recorded in camera lander images within either 'morraine' or 'shelf trough' habitats.

\begin{tabular}{|c|c|c|c|}
\hline Camera Lander Estimates & Moraine & Shelf Trough & Difference \\
\hline Richness (genera) & 15.7 genera $\mathrm{m}^{2}(0.5)$ & 5.7 genera $\mathrm{m}^{2}(1.8)$ & $2.8 \mathrm{x}$ \\
\hline Epifauna density & 77.3 ind $\mathrm{m}^{2}(0.31)$ & 12.3 ind $\mathrm{m}^{2}(0.09)$ & $6.3 \mathrm{x}$ \\
\hline VME density & 22.6 ind $\mathrm{m}^{2}(0.14)$ & 1.9 ind $\mathrm{m}^{2}(0.03)$ & $11.6 \mathrm{x}$ \\
\hline Unique taxa & 23 & 1 & $6.54 \mathrm{x}$ \\
\hline Carbon standing stock & 4.38 tonnes $/ \mathrm{km}^{2}(0.29)$ & 0.67 tonnes $/ \mathrm{km}^{2}(0.08)$ & $6.58 \mathrm{x}$ \\
\hline Annual carbon drawdown & 0.79 tonnes $/ \mathrm{km}^{2}(0.05)$ & 0.12 tonnes $/ \mathrm{km}^{2}(0.01)$ & $7.9 \mathrm{x}$ \\
\hline Carbon sequestration & 0.26 tonnes $/ \mathrm{km}^{2}(0.1)$ & 0.03 tonnes $/ \mathrm{km}^{2}(0.03)$ & \\
\hline
\end{tabular}

Agassiz trawls targeted across the same sites confirmed a similar dominance in abundance and masson hard moraine surfaces vs sediments there. This could be a result of geological youth of the sediments [7], the inability of many taxa to thrive in the sediment habitats or both [10]. Fishery observers around South Georgia have long reported higher fishing yields and by catch around these moraines and here we calculated that nearly 49\% (4,081t.yr) of South Georgia's benthic carbon accumulation occurs in just $12 \%$ of its continental shelf, at these moraines. It is likely that much of the benthic biodiversity on South Georgia (and other southern polar) shelves is limited by suitable habitat. Feeding and growth of benthos have been shown to correlate with phytoplankton duration, but not peak or integrated biomass [3], suggesting that competition for food is rare if it occurs. Therefore if the area of (rubble) habitat increased then benthic growth, carbon accumulation and sequestration could potentially increase by $400 \%$. If the shelf was all rubble, accumulation could be $0.79 \times 42,000=33,180$ tonnes C per year to the seabed at South Georgia alone. At current industry CCS values $\left(\sim 27 \mathrm{t}^{-1}\right)$, and over a hundred years (e.g. about the time scale of build, operation and decommission of a nuclear plant), the South Georgia seabed CCS could be worth £90 million (33180 x $100 y r s x \notin 27)$. At the South Orkney Islands, where benthic growth is almost double that at South Georgia [3] natural CCS could be worth $\sim £ 147$ million. Whilst the only natural occasion in which such shelves would be largely hard substrata is immediately following rapid glacial retreat (e.g. following glaciations), a directed effort 
to transport and drop rubble, as is done in tropical archipelagos to increase land area or in the South China sea to create islands, could be initiated to strategically capture carbon. Such a venture, like solar and wind-farms or ocean-iron fertilization would require financial scrutiny on the basis of the value of $\mathrm{CO}_{2}$ reduction and storage.

\section{Carbon continental shelf farms?}

Experimental deposition of rubble, i.e. trialling 'carbon draw down farms' on a polar continental shelf seabed does have a number of important potential problems. Firstly regions such as South Georgia and the South Orkney Islands are (major) marine protected areas, hotspots of Vulnerable Marine Environments (VME), important commercial fishery regions and key sites for rare and protected species, such as cetaceans and seabirds (particularly Wandering Albatrosses) [8,11]. Secondly it might require the agreement of many stakeholders, such as the Government of South Georgia and South Sandwich Islands, the Committee for Conservation of Antarctic Living Marine Resources, relevant conservation and fishery organisations. However rubble transport could be very expensive, both financially and in terms of carbon expenditure.

Would a limited experimental deployment of rubble to a currently sedimented area of a polar continental shelf negatively impact biodiversity? Clearly this would be the case for some sediment dwelling micro and macrobiota, but considerably less than historic bulldozing sediments off shelves by glaciations. Camera deployments show that densities of VMEs was 11 times greater on the moraines, no unique VMEs were found in the nonmoraine areas and only 1 unique taxon (a turbellarian flatworm) was seen on sediments. Historical records indicate that all of South Georgia endemics are known from the moraines, and nearly all only known from moraines. We suggest that it is likely that increased moraine area would correspondingly increase VME and endemic taxa populations, potentially making them more robust to climate change. It should provide more habitat and food for fish populations and benthic feeding ground for krill [12], thereby boosting fisheries and potential GSGSSI resources. It is not obvious that regional higher predator populations would be impacted especially by a small scale pilot deployment.

\section{Is rubble deposition energetically viable?}

If a trial of rubble deposition on a study area of South Georgia's continental shelf was supported environmentally the logistics and costs are a potential considerable hurdle. Large split-hopper vessels transporting $\sim 50,000 \mathrm{~m}^{3}$ would require $\sim 10$ drops to cover $\mathrm{a} \mathrm{km}^{2}$. As with establishing non-fossil fuel power generation the energy, costs and time to recoup investment are severe, but are they prohibitive? Minimizing costs would depend on maximizing vessel capacity, minimising rubble mining and transport distance. At South Georgia potentially enough rubble is available locally-but even this would generate payback in carbon capture over centuries (compared with decades from nuclear power). However polar benthic carbon accumulation per year has doubled in two decades in the region [2] and there is potential for further increases if foodprocessing and growth is temperature limited, all of which decreases payback time. At current levels of benthic carbon accumulation we calculate that CCS of $1 \mathrm{~km}^{2}$ of rubble on the South Georgia or South Orkney Islands shelf would only be worth $\sim £ 2140$ and $\sim £ 3500$, which is nearly two orders of magnitude lower than the cost of transport. Payback time would thus be $\sim 10,000$ years. If the pilot area was Arctic rather than Antarctic, the transport element could be drastically reduced (e.g. from Tromso, Norway) there by cutting cost and energy requirements of deployment, perhaps to give a 1000 year pay back. Even if polar carbon accumulation doubles again in the next two decades the payback time would likely be considered too distant, what might make continental shelf carbonfarming viable is a considerable increase in the valuing of CCS and/ or large scale drone hopper ships. Even theoretical calculations and discussion of natural carbon capture demonstrate the value of hidden biodiversity and ecosystem services.

\section{Supplemental Information}

Supplemental information includes supplemental experimental procedures, a supplemental table and supplemental references.

\section{Supplemental experimental procedures}

The bespoke Shelf Underwater Camera System (SUCS) was deployed at 30 sites around South Georgia (SG) and 4 sites at the South Orkney Islands (SOI). This system consists of a high resolution digital stills and video camera which transmits live images to a desktop computer on RRS James Clark Ross. It has twin dimmable lights which cover contrasting directions and USBL direction beacon to communicate position with the vessel (to generate corrected GPS location). SG and SOI are the locations of one of the world's largest Marine Protected Areas and the first High seas marine protected area respectively. Nearly 400 images were taken, as well as Agassiz trawl deployments to collect specimens from the same locations. The locations of study sites are given in JR 262 and JR 287 cruise reports, which are available on request from the Natural Environment Research Council or study authors.

Counts of epifaunal density were made from high resolution images as were counts of what the Committee for Conservation of Antarctic Marine Living Resources (CCAMLR) considers representatives of Vulnerable Marine Ecosystems (large 3D calcareous organisms such as corals, hydrocorals, sponges, some bryozoans and some polychaetes). Counts were also made of taxa (morphotypes) only occurring in one of the two study habitats; rubble (moraine) and sediment (shelf trough). Carbon drawdown was estimated using a combination of literature values [13-16] with adjustment for size of the representatives of differing taxa. A number of contrasting ways of estimation of carbon drawdown for Southern Ocean localities have been attempted. The current study estimated carbon standing stock for each of the two habitats at 4.38 tonnes. $\mathrm{km} 2 \times 12.3 \%$ (proportion of shelf that is moraine) $\mathrm{x}$ 42,000 sqkm (South Georgia) shelf area $=22,627$ tonnes. This was then added to the equivalent value for the shelf trough $(23,811 t)$; $22617+23811=46,428$ tonnes standing stock of seabed carbon in 
epifauna. Recent literature [17] estimated annual carbon drawdown at South Georgia from scaling up of direct measurement of one element of biodiversity there; bryozoans (approximately median in terms of Production/Biomass value). Our estimate (8,345tCyr1) derived across all visible taxa in seabed images differs little from that scaled up from bryozoans ( 7300tCyr-1) suggesting the estimates are fairly robust. Such a value seems reasonable for many of the key Carbon drawdown taxa and possibly even for sponges [18] but considerably too high for the corals there. Conversion to carbon sequestration was estimated on the basis of proportion of skeletal material and judgments on the likelihood for burial and fossilisation (high for bryozoans, shelled molluscs, calcareoustubed polycheate worms, hard corals and hydrocorals).

\section{Acknowledgement}

Thanks to Carl Robinson for technical development of the Shelf Underwater Camera System (SUCS), Chris Fussell for preliminary image analysis, Oliva Martin-Sanchez for construction of the map in Figure 2, and Randolph Sliester for discussions on shipping inner shelf moraines (bottom).

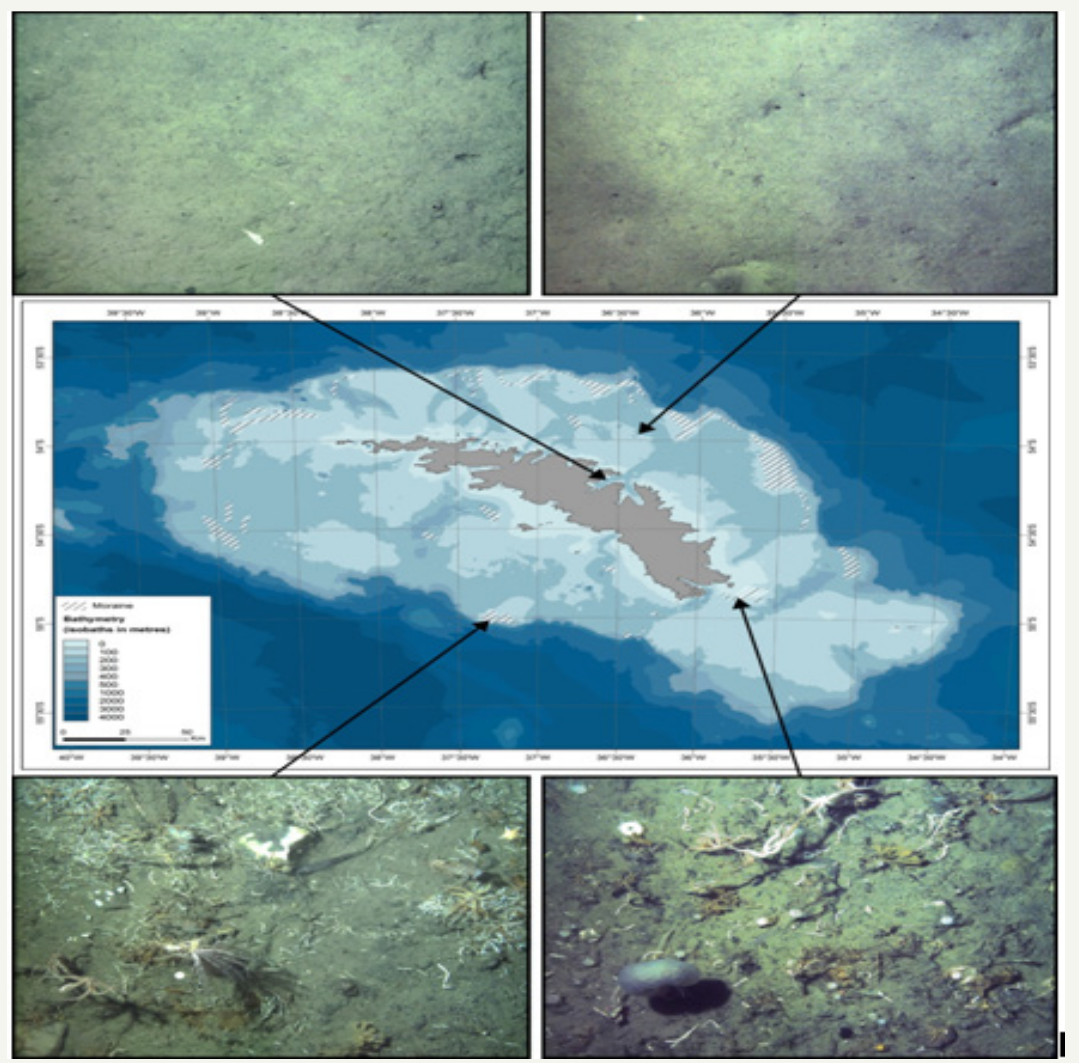

Figure 2: Continental shelf, moraines and seabed imagery at South Georgia, Southern Ocean. Epibenthic life on fjordic and shelf muds (top), shelf break and inner shelf moraines (bottom).

\section{References}

1. Barnes DKA (2015) Antarctic sea ice losses drive gains in benthic carbon drawdown. Curr Biol 25(18): 789-790.

2. Sterner T (2015) Economics: Higher costs of climate change. Nature 527: $177-178$.

3. Barnes DKA, Ireland L, Hogg OT, Morley S, Enderlein P, et al. (2016) Why is the South Orkney Island shelf (the world's first high seas marine protected area) a carbon immobilization hotspot? Glob Chang Biol 22(3): 1110-1120.

4. Peck LS, Barnes DKA, Cook AJ, Fleming AH, Clarke A (2010) Negative feedback in the cold: ice retreat produces new carbon sinks in Antarctica. Glob Chang Biol 16(9): 2614-2623.

5. Filinger L, Janussen D, Lundalv T, Richter C (2013) Rapid glass sponge expansion after climate-induced Antarctic ice shelf collapse. Curr Biol 23(14): 1330-1334.

6. Fuchs H, Magdon P, Kleinn C, Flessa H (2009) Estimating above ground carbon in a catchment of the Siberian forest tundra: combining satellite imagery and field inventory. Remote Sens Environ 113(3): 518-531.

7. Graham AGC, Fretwell PT, Larter RD, Hodgson D, Wilson CK, et al. (2008) A new bathymetric compilation highlighting extensive paleo-ice sheet drainage on the continental shelf, South Georgia, sub-Antarctica, Geochem Geophys Geosyst 9(7): 701.

8. Hogg OT, Barnes DKA, Griffiths HJ (2011) Highly diverse, poorly studied and uniquely threatened by climate change: an assessment of marine biodiversity on South Georgia's continental shelf. PLoS One 6(5): 19795.

9. Brinkhuis H, Schouten S, Collinson ME, Sluijs A, Sinninghe Damsté JS (2006) Episodic fresh surface waters in the Eocene Arctic Ocean. Nature 441(7093): 606-609.

10. Barnes DKA, Sands CJ, Hogg OT, Robinson BJO, Downey RV, et al. (2016) Biodiversity signature of the last glacial maximum at South Georgia, Southern Ocean. J Biogeograph 43(1): 2391-2399.

11. Taylor MC, Yesson C, Agnew DJ, Mitchell RE, Rogers AD (2013) Using fisheries by-catch data to predict octocoral habitat suitability around South Georgia. J Biogeog 40(9): 1688-1701. 
12. Schmidt K, Atkinson A, Steigenberger S, Lindsay MCM, Pond DW, et al. (2011) Seabed foraging by Antarctic krill: Implications for stock assessment, bentho-pelagiccoupling, and the vertical transfer of iron. Limnol Oceanogr 56(4): 1411-1428.

13. Pinkerton MH, Bradford-Grieve J, Bowden DA (2010) Benthos: trophic modelling of the Ross Sea. Supporting document to CCAMLR science 17: 1-31.

14. Salonen K, Sarvala J, Hakala I, Viljanen ML (1976) Relation of energy and organic-carbon in aquatic invertebrates. Limnology and Oceanography 21(5): 724-730.
15. Arntz WE, Brey T, Gallardo VA (1994) Antarctic zoobenthos. Oceanography and Marine Biology: an Annual Review 32: 241-304.

16. Mühlenhardt-Siegel U (1988) Some results on quantitative investigations of macrozoo-benthos in the Scotia Arc (Antarctica). Polar Biology 8: 241-248.

17. Barnes DKA (2015) Antarctic sea ice losses drive gains in benthic carbon drawdown. Current Biology 25(18): 789-790.

18. Fillinger L, Janussen D, Lundälv T, Richter C (2013) Rapid glass sponge expansion after climate-induced Antarctic ice shelf collapse. Curr Biol 23(14): 1330-1334.

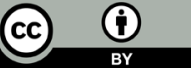

Creative Commons Attribution 4.0 International License

For possible submissions Click Here
Submit Article

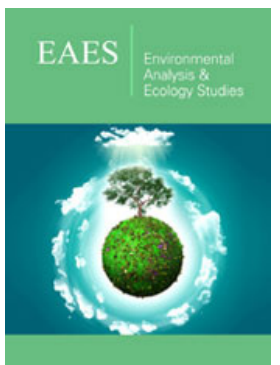

Environmental Analysis \& Ecology Studies

\section{Benefits of Publishing with us}

- High-level peer review and editorial services

- Freely accessible online immediately upon publication

- Authors retain the copyright to their work

- Licensing it under a Creative Commons license

- Visibility through different online platforms 